\title{
Use of oxytetracycline for the treatment of tremor disease in the Chinese mitten crab Eriocheir sinensis
}

\author{
Tingming Liang, Qi Feng, Ting Wu, Wei Gu, Wen Wang* \\ Jiangsu Key Laboratory for Biodiversity \& Biotechnology, College of Life Sciences, Nanjing Normal University, \\ Nanjing 210046, PR China
}

\begin{abstract}
The causative agent of tremor disease (TD) in the Chinese mitten crab Eriocheir sinensis has been shown to be a member of the genus Spiroplasma. In the present study, a susceptibility test indicated that oxytetracycline (OTC) has both a high degree of efficacy in the inhibition of Spiroplasma and a broad range of safe concentrations. Treatment experiments showed that the best concentration of OTC for use against TD was $40 \mathrm{mg}^{\text {OTC kg}}{ }^{-1} \mathrm{crab}$ weight. Acute toxicity experiments demonstrated that the 24 and $48 \mathrm{~h}$ median lethal dosages $\left(\mathrm{LD}_{50}\right)$ of OTC for this species of crab were 366 and $340 \mathrm{mg}$ OTC kg-1 $^{-1}$ crab body weight, respectively, while the safe concentration was $82.5 \mathrm{mg}$ OTC $\mathrm{kg}^{-1} \mathrm{crab}$ weight. We suggest that OTC has potential as a highly effective inhibitor of Spiroplasma pathogens in aquatic animals and has been proven to be a potent, safe and low cost cure for TD. This represents a novel use of OTC in the therapeutic treatment of an aquacultural disease caused by a Spiroplasma pathogen.
\end{abstract}

KEY WORDS: Oxytetracycline $\cdot$ Spiroplasma $\cdot$ Tremor disease $\cdot$ Acute toxicity $\cdot$ Chinese mitten crab $\cdot$ Eriocheir sinensis

Resale or republication not permitted without written consent of the publisher

\section{INTRODUCTION}

The Chinese mitten crab Eriocheir sinensis is one of the most important cultivated species in Southeast Asia. The farming of $E$. sinensis has recently increased in China, from $200000 \mathrm{t}$ in 2000 to $420000 \mathrm{t}$ in 2004 (Yuan 2005). However, frequent outbreaks of disease have caused drastic decreases in production and catastrophic economic losses.

With the development of intensive aquaculture, epidemics of tremor disease (TD) caused by spiroplasma occur frequently in farmed Eriocheir sinensis populations. TD was first found in 1994 and spread quickly; by 1998 the disease had spread to most crab aquaculture facilities in China (Huang 2000). TD occurs seasonally from May to October in this E. sinensis, with most disease associated with high water temperatures $\left(19\right.$ to $\left.28^{\circ} \mathrm{C}\right)$. Crabs infected with TD show signs of weakness, anorexia, intense paroxysmal tremors and will ultimately die. Analysis of randomly collected samples suggests that the prevalence was $34.3 \%$ in Anhui province in 1998 (Wei 1999). The disease has spread quickly in the Jiangsu, Anhui and Zhejiang provinces in southeastern China, causing mortality rates of 30 to $90 \%$. The disease has proven difficult to control and therefore causes serious losses (Wang \& $\mathrm{Gu}$ 2002).

Following the discovery of TD in 1994, investigators proposed 5 possible etiologies. These included a putative virus (Chen et al. 1999, He et al. 1999, Lu 1999a, Sun et al. 2000), environmental bacteria (Yang \& Cai 1998, Wei 1999, Lu et al. 1999b, Shen et al. 2000, Xu \& Xu 2002), environmental deterioration (Pan 1998), a combination of the aforementioned etiologies (Zhou \& Yang 2000) and a rickettsial-like organism (RLO) (Wang \& Gu 2002, Wang et al. 2002, 2003a, Zhang et al. 2002). An RLO was finally demonstrated to be the cause of TD by pathology and artificial transmission 
experiments (Wang \& Gu 2002, Wang et al. 2002). Similar results were obtained in subsequent studies (Zhang et al. 2002, Wang et al. 2003a). Subsequent isolation and analysis of the 16S rRNA gene, which was the 'gold standard' of microbiological classification, confirmed the agent to be a spiroplasma (Wang et al. 2003b, 2004a,b). This was the first spiroplasma to be found in aquatic crustaceans and it began to change our understanding of the host range of these organisms (Christensen et al. 2005, Regassa \& Gasparich 2006). Koch's postulates were later fulfilled for the spiroplasma, providing definitive proof that this agent was the cause of TD (Wang et al. 2004a).

As mentioned above, many scholars have studied TD since it became epidemic in the Chinese mitten crab (Pan 1998, Yang \& Cai 1998, Wei 1999, Huang 2000, Shen et al. 2000). Although the TD pathogen had not been accurately characterized, different medical compounds were administered as therapies, but no efficient disease controls were found. In the present study we examined the susceptibility of spiroplasma to 8 different chemical compounds used in aquaculture: calcium oxide, niclosamide, deltamethrin, cupric sulfate pentahydrate, potassium permanganate, bromochlorodimethylhydantoin, Benzylpenicillin and oxytetracycline (OTC). Many antibacterial compounds have been tested in aquaculture systems, including calcium oxide and potassium permanganate for their chemotherapeutic control of ectoparasites (Saprolegnia, Trichodina, Myxobolus, Hemiclepsis, Argulus, and Posthodiplostomum) attached to cultured fish (Singhal et al. 1986). Niclosamide belongs to the anthelminthic family of medicines and has been used to treat broad or fish tapeworm, dwarf tapeworm and beef tapeworm infections (WHO 1984). The anthelminthic efficacy of niclosamide for the treatment of turbot infected naturally with the platyhelminth Bothriocephalus scorpii has been reported (Sanmartín Durán et al. 1989). Cupric sulfate pentahydrate has been used to treat protozoan infections of crustacea (Chen et al. 2006). Bromochlorodimethylhydantoin has been used as an efficient broad-spectrum sanitizer against bacteria whilst benzylpenicillin is a group of lactam antibiotics used in the treatment of bacterial infections caused by susceptible, usually Gram-positive, organisms (McCoy \& Wireman 1989). OTC, which belongs to the tetracycline antibacterial group, gained USFDA approval for use in aquatic poikilothermic food species as a broad-spectrum antibiotic (USFDA 1996). OTC binds to the 30S subunit of the microbial $70 \mathrm{~S}$ ribosomes, inhibiting protein synthesis by blocking the attachment of aminoacyltRNA units (Levy 1984, Chopra 1985). It has been widely used for decades for the treatment of bacterial diseases in aquaculture, mainly due to its efficacy, low cost and high utility. Many studies have confirmed that
OTC can be used to treat aquatic diseases, and it is now used worldwide (Anderson \& Jeney 1992, Lunden et al. 2002, Miranda \& Zemelman 2002, Rigos et al. 2002, 2003, Delepee \& Pouliquen 2003, Delepee et al. 2004, Reed et al. 2004, Ueno et al. 2004). The efficacy of OTC has been demonstrated by its ability to treat bacterial infections in fish and vibrioses and necrotizing hepatopancreatitis (NHP) in farmed shrimp (Reed et al. 2004). OTC has great potential as an antimicrobial in shrimp farming (Corliss et al. 1977, Takahashi et al. 1985, Williams \& Lightner 1988), and it has been used for the treatment of systemic bacterial infections in farmed finfish (Bjorklund \& Bylund 1991). However, the effectiveness of OTC as a therapy for TD caused by spiroplasma in the Chinese mitten crab has not previously been investigated.

Based on the susceptibility test results, we attempted to identify the compound which was most effective at inhibiting spiroplasma. Subsequently we determined the safe concentration of the compound for the Chinese mitten crab using acute toxicity experiments. Our objective was therefore to identify the most appropriate compound and ideal concentration for the treatment of spiroplasma-induced TD. This analysis will provide essential information to the crab farming industry and to the freshwater aquaculture industry as a whole.

\section{MATERIALS AND METHODS}

Crab specimens, spiroplasma and compounds. Chinese mitten crabs were collected from Baoying County, Jiangsu province in China, and were randomly tested for the presence of spiroplasma by PCR (Ding et al. 2007). Spiroplasma was isolated from crabs with TD (Wang et al. 2003b) and maintained in pure culture in M1D medium (Hackett et al. 1987, Moulder et al. 2002). The cultures were observed for daily color change resulting from respiratory acidification and the titer was expressed in color-changing units (CCU $\mathrm{ml}^{-1}$ ), and the CCU ml ${ }^{-1}$ of the isolates was $10^{8}$ spiroplasmas $\mathrm{ml}^{-1}$ at the exponential phase in the spiroplasma culture (Ding et al. 2007).

All chemicals (calcium oxide, niclosamide, deltamethrin, cupric sulfate pentahydrate, potassium permanganate, bromochlorodimethylhydantoin, benzylpenicillin and OTC) were analytical grade and purchased from Sigma-Aldrich Chemical. Compounds were diluted to a new concentration using sterile $0.9 \%$ physiological saline and stored at $4{ }^{\circ} \mathrm{C}$.

Susceptibility testing (Expt 1). All 8 therapeutic agents listed above were used in the spiroplasma susceptibility tests. The minimum inhibitory concentration (MIC) and the minimum bactericidal concentration (MBC) values were determined using the standardized 
dilution method described by (Bruun et al. 2000). Diffusion tests were performed using diluted pleuropneumonia-like organism (PPLO) agar (Difco Laboratories) (Bruun et al. 2000). Commercial discs with a diameter of $90 \mathrm{~mm}$ and containing the 8 compounds were used as described by Dalsgaard \& Madsen (2000). All tests were performed in duplicate.

Spiroplasma challenge experiments and treatment experiments (Expt 2). A total of 160 healthy crabs averaging $50 \mathrm{~g}$ in weight were used and kept in aerated tanks at $27 \pm 1^{\circ} \mathrm{C}$ for challenge and treatment experiments; 120 healthy crabs were randomly divided into 6 therapy groups (Groups 3 to 8 ) of approximately the same number of individuals and each crab was inoculated with $0.1 \mathrm{ml}$ of pure cultured spiroplasma $\left(10^{8}\right.$ spiroplasma $\mathrm{ml}^{-1}$ ). Twenty other crabs were inoculated with $0.1 \mathrm{ml}$ pure cultured spiroplasma as a positive control group (Group 2) and an additional 20 crabs were inoculated with $0.1 \mathrm{ml}$ M1D medium to serve as a negative control group (Group 1). All crabs were observed daily and a hemolymph sample tested by PCR and ELISA every $3 \mathrm{~d}$ to determine whether they were infected with spiroplasma. Before collecting hemolymph, the body of the crab was cleaned with water, disinfected using $75 \%$ alcohol, a needle introduced through the joint between the pereiopod and the thorax and a small aliquot of blood ( 0.05 ml) collected. After $24 \mathrm{~h}$ post-injection, crabs were treated by injection with $0.1 \mathrm{ml}$ OTC at different concentrations $(0.5,2.5,5.0,10$, 20 or $50 \mathrm{~g} \mathrm{l}^{-1}$ ). The positive control group was injected with $0.1 \mathrm{ml} 0.9 \%$ sodium chloride solution. The crabs were then observed daily and the number of dead individuals recorded. The experiment was terminated when all crabs in the positive control group had died.

Detection of spiroplasma by PCR and ELISA. Spiroplasma DNA was extracted from hemolymph samples by the Chelex-100 method (Ding et al. 2007) and fragments amplified by PCR using the following pair of primers: forward PCR primer F28 (5'-CGC AGA CGG TTT AGC AAG TTT GGG-3') and reverse primer R5 (5'-AGC ACC GAA CTT AGT CCG ACA C-3') (Bastian et al. 2004). PCR reactions of $30 \mu$ l contained $0.2 \mu \mathrm{l}$ DNA polymerase, $2 \mu$ primer mixture, $3 \mu$ l 10X STR buffer (including dNTP and $\mathrm{Mg}^{2+}$, Promega), $5 \mu$ DNA template and $19.8 \mu \mathrm{l}$ sterile water. The PCR was performed using a PTC-100 thermal cycler (Bio-Rad) with the following cycle conditions: (1) initial activation at $96^{\circ} \mathrm{C}$ for $2 \mathrm{~min}$; (2) 30 cycles of $94^{\circ} \mathrm{C}$ for $1 \mathrm{~min}, 65^{\circ} \mathrm{C}$ for $50 \mathrm{~s}$ and $72^{\circ} \mathrm{C}$ extension for $1.5 \mathrm{~min}$; (3) a final extension at $72^{\circ} \mathrm{C}$ for $10 \mathrm{~min}$. The presence of amplified PCR products was confirmed by using a $1 \%$ agarose gel followed by UV visualization after ethidium bromide staining. The presence of a specific band at about $271 \mathrm{bp}$ in the electrophoresis results indicated that the crab had been infected by spiroplasma (Fig.1).



Fig. 1. PCR amplification of genomic DNAs of spiroplasma with primer pairs F28/R5. Lane M: DL2000 DNA marker, Lane 1: Group 1 was a normal group of Eriocheir sinensis without inoculation and treatment, Lane 2: Group 2 was a positive control group inoculated with spiroplasma and then treated with $0.1 \mathrm{ml}$ of $0.9 \%$ sodium chloride solution. Lanes 3 to 8 : Groups 3 to 8 were treated with different concentrations of oxytetracycline (OTC) after inoculation with spiroplasma

An ELISA was also carried out to detect spiroplasma using 96-well plates. The hemolymph was diluted 1:20 with distilled water and incubated for $30 \mathrm{~min}$ at $37^{\circ} \mathrm{C}$ (positive control; negative control was prepared in the same way). The wells were washed 3 times with phosphate-buffered saline Tween-20 (PBST) (8 g NaCl, $0.2 \mathrm{~g} \mathrm{KCl}, 1.44 \mathrm{~g} \mathrm{Na} \mathrm{HPO}_{4}, 0.24 \mathrm{~g} \mathrm{KH} \mathrm{KH}_{4}, 2 \mathrm{ml}$ Tween-20, pH adjusted to 7.2 and volume to 11 with distilled $\mathrm{H}_{2} \mathrm{O}$ ). A 1:400 dilution of rabbit polyclonal antiserum (produced by our lab) was incubated for 30 min at $37^{\circ} \mathrm{C}$. After discarding the unbound polyclonal antibody, goat anti-rabbit IgG (horseradish peroxidase, HRP) (Sigma) at a dilution of 1:3000 was added and incubated for $30 \mathrm{~min}$ at $37^{\circ} \mathrm{C}$, followed by 3 washes with PBST. Substrate solutions were prepared and added after $10 \mathrm{~min}$ at room temperature: $\mathrm{Na}_{2} \mathrm{HPO}_{4} \cdot 12 \mathrm{H}_{2} \mathrm{O} 71.7 \mathrm{~g}$ with distilled water added to $1000 \mathrm{ml}_{;} \mathrm{C}_{6} \mathrm{H}_{8} \mathrm{O}_{7} \cdot \mathrm{H}_{2} \mathrm{O}$ citric acid $19.2 \mathrm{~g}$ with distilled water added to $1000 \mathrm{ml} ; 51.4 \mathrm{ml} \mathrm{Na} \mathrm{HPO}_{4} \cdot 12 \mathrm{H}_{2} \mathrm{O}$ added to $48.6 \mathrm{ml} \mathrm{C}_{6} \mathrm{H}_{8} \mathrm{O}_{7} \cdot \mathrm{H}_{2} \mathrm{O}$ to provide a $10 \mathrm{ml}$

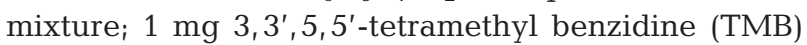
added to $30 \% \mathrm{H}_{2} \mathrm{O}_{2} 0.05 \mathrm{ml}$. The color reaction was stopped by the addition of $2 \mathrm{M} \mathrm{H}_{2} \mathrm{SO}_{4}$. The color development was monitored visually and the absorbance was measured at $450 \mathrm{~nm}$ using an automatic ELISA reader (Model 680 Microplate Reader; Bio-Rad) (Table 1). A color change (yellow) in the substrate solution indicated that the crab was infected with spiroplasma.

Oxytetracycline acute toxicity tests (Expt 3). Stock solutions of OTC were prepared in the study. A total of 315 healthy crabs were used and kept in aerated tanks at $27 \pm 1^{\circ} \mathrm{C}$ for OTC acute toxicity tests. Animals were 
Table 1. The optical density (OD) of the spiroplasma-antibody complex in the hemolymph of different groups of Eriocheir sinensis measured at $450 \mathrm{~nm}$ using an automatic ELISA reader. Group 1 was a normal group without inoculation and treatment. Group 2 was a positive control group inoculated with spiroplasma and then treated with $0.1 \mathrm{ml}$ of $0.9 \%$ sodium chloride solution. Groups 3 to 8 were treated with different concentrations of oxytetracycline (OTC) after inoculation with spiroplasma (see 'Spiroplasma challenge experiments and treatment experiments'). Group 9 was the pure cultured spiroplasma as a positive control. Group 10 was blood from untreated crabs (control). Group 11 was a blank control in the experiment

\begin{tabular}{|cccccccccccc|}
\hline & 1 & 2 & 3 & 4 & 5 & 6 & 7 & 8 & 9 & 10 & 11 \\
\hline $\mathrm{OD}_{450 \mathrm{~nm}}$ & 0.10 & 0.75 & 0.72 & 0.69 & 0.68 & 0.82 & 0.71 & 0.68 & 0.92 & 0.11 & 0.05 \\
\hline
\end{tabular}

and bromochlorodimethylhydantoin showed only a slight inhibitory effect.

\section{Spiroplasma challenge and treatment experiments (Expt 2)}

The results of the challenge and treatment experiments are presented in Fig. 2. An $80 \%$ survival rate, higher than that in any other treatment, was achieved with OTC at a concentration of $20 \mathrm{~g} \mathrm{l}^{-1}$. The current data therefore suggest that this concentration is opti-

randomly divided into 9 equally sized groups. Seven groups (Groups 1 to 7 ) were injected with $0.05 \mathrm{ml}$ of OTC solution at 1 of 7 different concentrations $(50,20,10,5.0$, 2.5, 0.5 or $0 \mathrm{~g} \mathrm{l}^{-1}$ ) and Group 8 remained untreated as a blank control. The last group (Group 9) was injected with the same volume of $0.9 \%$ physiological saline as a negative control. The number of dead crabs was recorded at 24 and $48 \mathrm{~h}$ intervals.

Data analysis. The OTC results, their 95\% CIs and chi-square goodness of fit were calculated with the SPSS 13.0 program. The statistical significance of differences in survival between OTC concentrations was examined using a 1-way ANOVA after testing for normality and data homogeneity. If the homogeneity of variance was violated, a log transformation of the data was performed prior to further analysis. If any significant differences were detected $(p<0.05)$, differences among treatments were identified using Tukey's Honestly Significant Difference (HSD) test. A logistic regression was used (Zar 1999) to determine the relationship between survival and OTC concentration.

\section{RESULTS}

\section{Susceptibility tests (Expt 1)}

MIC and MBC values of 8 compounds were obtained by susceptibility tests (Table 2). These compounds were ranked according to the extent to which they inhibited spiroplasma as follows: OTC > deltamethrin $>$ potassium permanganate $>$ cupric sulfate pentahydrate $>$ bromochlorodimethylhydantoin $>$ calcium oxide $>$ niclosamide $=$ benzylpenicillin. OTC had the lowest MIC and MBC (0.04 and $0.62 \mathrm{mg} \mathrm{l}^{-1}$, respectively), indicating it was more effective than the other compounds at inhibiting spiroplasma. Benzylpenicillin and niclosamide showed no inhibitory effect even though they were administered at a dose 10 times higher than normal. Calcium oxide, deltamethrin, cupric sulfate pentahydrate, potassium permanganate mal for the treatment of TD. Since the mean crab weight was $50 \mathrm{~g}$, the best concentration of OTC to treat TD can be calculated as $40 \mathrm{mg}$ OTC $\mathrm{kg}^{-1}$ crab weight.

Eight groups were used in the challenge and treatment experiments. Each was injected with spiroplasma and treated with a different concentration of OTC $(0.5$, $2.5,5.0,10,20$ and $50 \mathrm{~g} \mathrm{l}^{-1}$ ) or left as an untreated control. The correlation between days post-treatment and survival in each group is displayed in Fig. 3, from which it is apparent that Group 7 had the highest survival rate $(80 \%)$.

\section{Acute toxicity tests (Expt 3)}

The number of crabs which had died 24 and $48 \mathrm{~h}$ following treatment with OTC at the different concentrations are shown in Table 3. The correlation between the mean 24 and 48 h mortality rates (\%) with $\log _{10}(C)$ is illustrated in Fig. 4 (where $C$ is OTC concentration). No crabs died when the concentration of OTC was $0 \mathrm{~g}$ $\mathrm{l}^{-1}$ or the same volume of physiological saline was injected. In contrast, an OTC concentration of $50 \mathrm{~g} \mathrm{l}^{-1}$ was associated with a $100 \%$ mortality rate. The mean crab weight was $5.5 \pm 0.5 \mathrm{~g}$ in the acute toxicity tests. The 24 and $48 \mathrm{~h}$ median lethal dosages $\left(\mathrm{LD}_{50}\right)$ of OTC

Table 2. Minimum inhibitory concentrations (MIC) and minimum bactericidal concentration (MBC) of 8 compounds against spiroplasma in the susceptibility tests (Expt 1). -: no inhibition to spiroplasma detected

\begin{tabular}{|lcc|}
\hline Compound name & MIC $\left(\mathrm{mg} \mathrm{l}^{-1}\right)$ & $\mathrm{MBC}\left(\mathrm{mg} \mathrm{l}^{-1}\right)$ \\
\hline Oxytetracycline & 0.04 & 0.62 \\
Calcium oxide & 400 & 1000 \\
Niclosamide & - & - \\
Deltamethrin & 7.8 & 37.5 \\
Cupric sulfate pentahydrate & 15.6 & 25 \\
Bromochlorodimethylhydantoin & 20 & 400 \\
Potassium permanganate & 12.5 & 31.25 \\
Benzylpenicillin & - & - \\
& & \\
\hline
\end{tabular}




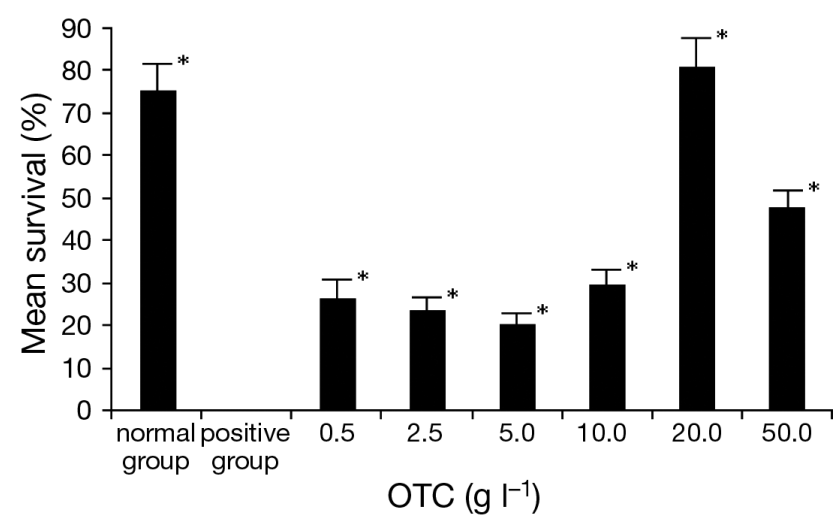

Fig. 2. Eriocheir sinensis. Inoculation and treatment experiments (Expt 2) showing correlation of mean survival rate and oxytetracycline (OTC) concentration. Group 1 was a normal group without inoculation and treatment. Group 2 was a positive control group inoculated with spiroplasma and then treated with $0.1 \mathrm{ml}$ of $0.9 \%$ sodium chloride solution. Groups 3 to 8 were treated with different concentrations of OTC after inoculation with spiroplasma. Highest mean survival rate was $\sim 80 \%$ in Group 7, lowest was $20 \%$ in Group 2. ${ }^{*}$ Significant difference $(p<0.05)$ after 1 -way ANOVA analysis followed

by a Tukey's Honestly Significant Difference (HSD) test

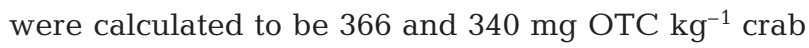
weight, respectively, while the safe concentration was $82.5 \mathrm{mg}$ OTC $\mathrm{kg}^{-1}$ crab weight.

\section{DISCUSSION}

Eriocheir sinensis is an economically important aquaculture species in China. However, TD caused by spiroplasma has become epidemic in farmed crab. Spiroplasma are wall-less Gram-positive bacteria and are amongst the smallest unicellular organisms in the world (Regassa \& Gasparich 2006). The agent can pass through membrane filters with pores of $220 \mathrm{~nm}$ diameter and can be cultivated in M1D or R2 media in vitro (Tully et al. 1977, Whitcomb 1983, Hackett et al. 1987, Moulder et al. 2002). It is a helical, motile, disease-causing genus of bacteria first found in insects and plants in the 1970s (Saglio et al. 1973, Clark 1982, Williamson et al. 1999, Christensen et al. 2005). Honeybee studies provided information on the prevention of spiroplasma-induced crawling disease with antibiotics; these studies made it apparent that spiroplasmas are susceptible to tetracycline. The present study focused on the inhibition of spiroplasma responsible for TD. Susceptibility tests were performed in

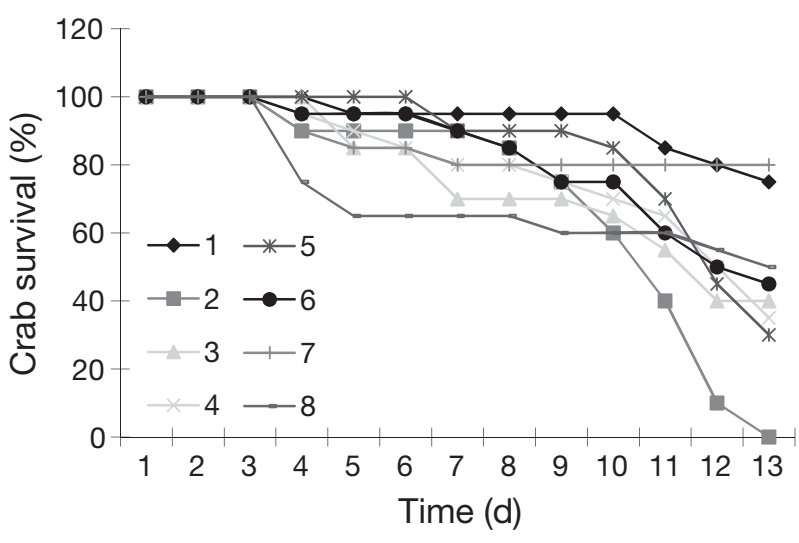

Fig. 3. Eriocheir sinensis. Relationship between time (d) following infection with spiroplasma and crab survival when treated with oxytetracycline (OTC) (Expt 2). Survival decreased with time. Group 2 was the positive control. Group 7 had the highest survival $(80 \%)$ in the treatment tests. All crabs in Group 2 had died by Day 13 and the treatment tests were concluded

order to establish which compounds effectively inhibited spiroplasma. The results of these tests demonstrated that OTC and deltamethrin had higher efficacies than the other compounds examined and that OTC had a broad range of safe concentrations. In recent years, deltamethrin has been used by crab farmers to clean ponds in the north Jiangsu province of China. This approach may inhibit spiroplasma to some extent, and the morbidity resulting from TD appears to have decreased a little. All compounds studied had some valuable implications for TD. The MIC of potassium permanganate was $12.5 \mathrm{mg} \mathrm{l}^{-1}$ and it was also highly soluble, allowing it to be used to prevent TD through bath exposure. In the case of OTC, the use of oral administration through mixing with the feed may provide a more convenient and feasible route for application than injection.

Table 3. Eriocheir sinensis. Concentration of oxytetracycline (OTC) used in the acute toxicity tests (Expt 3) and number of dead crabs in each group 24 and $48 \mathrm{~h}$ after treatment. Group 8 did not receive any injection

\begin{tabular}{|lcccc|}
\hline Group & $\begin{array}{c}\text { Concentration } \\
\text { of OTC }\left(\mathrm{g} \mathrm{l}^{-1}\right)\end{array}$ & $\begin{array}{c}\text { No. of } \\
\text { crabs }\end{array}$ & $\begin{array}{c}\text { Dead crabs } \\
\text { after 24 h }\end{array}$ & $\begin{array}{c}\text { Dead crabs } \\
\text { after 48 h }\end{array}$ \\
\hline 1 & 50 & 35 & 35 & 35 \\
2 & 20 & 35 & 31 & 32 \\
3 & 10 & 35 & 27 & 28 \\
4 & 5.0 & 35 & 24 & 24 \\
5 & 2.5 & 35 & 6 & 7 \\
6 & 0.5 & 35 & 5 & 5 \\
7 & 0 & 35 & 0 & 0 \\
8 (blank group) & - & 35 & 0 & 0 \\
9 (negative group) & 0 (0.9\% physiol- & 35 & 0 & 0 \\
\multicolumn{7}{l}{ ogical saline) } \\
\end{tabular}



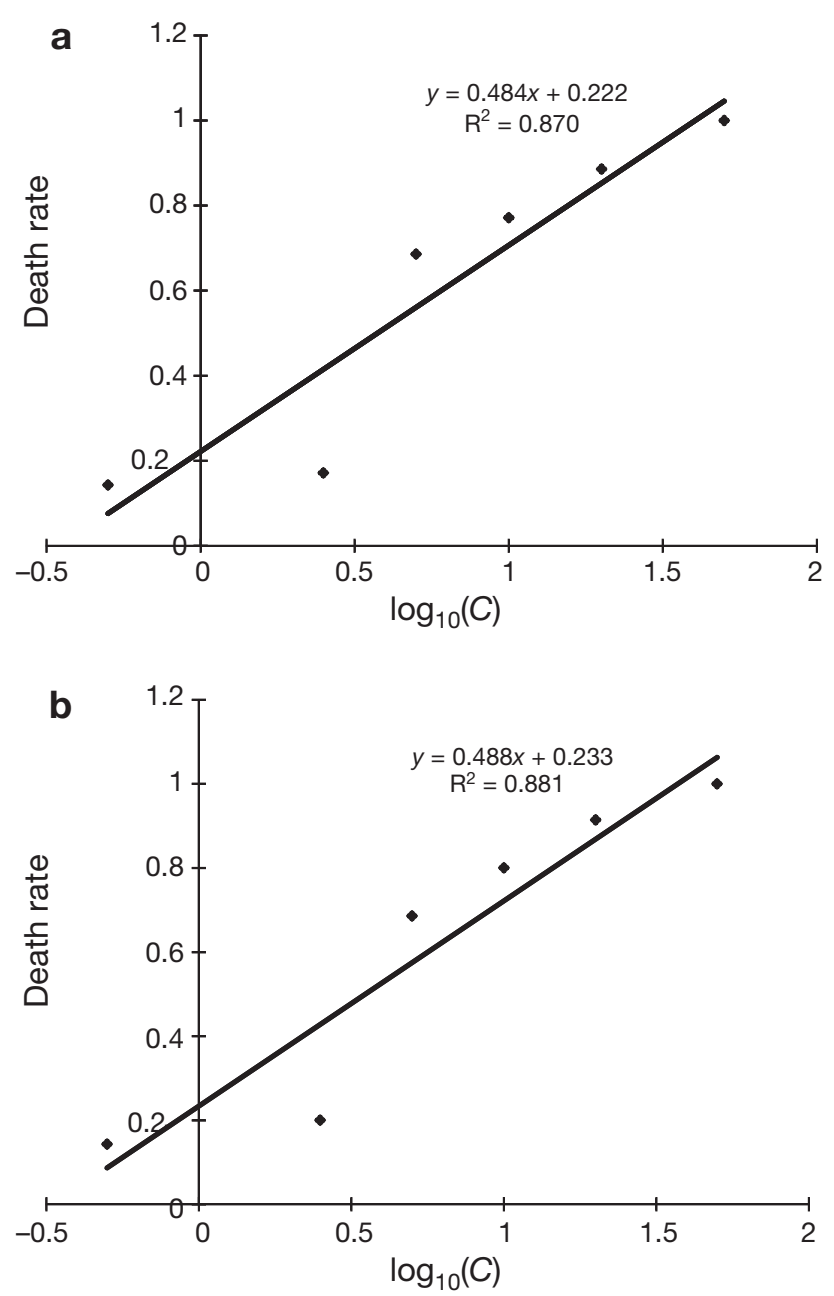

Fig. 4. Eriocheir sinensis. Acute toxicity tests (Expt 3) at (a) 24 and (b) $48 \mathrm{~h}$. Correlations between the mean 24 and $48 \mathrm{~h}$ mortality rate and $\log _{10}(C)$ are shown. $C$ : oxytetracycline (OTC) concentration $\left(\mathrm{g} \mathrm{l}^{-1}\right)$

The challenge and treatment experiment model used in the present study had previously been established by Wang \& Gu (2002). In this earlier work, OTC was used to control bacterial hemorrhagic septicemia (etiological agent, Aeromonas hydrophila), ulcer disease (etiological agent, Haemophilus piscium), pseudomonad disease (etiological agents are secondary pathogens belonging to the genus Pseudomonas) and furunculosis (etiological agent, A. salmonicida) in salmonids cultured in water temperatures higher than or equal to $9^{\circ} \mathrm{C}$ (USFDA 1996). The present study was designed to expand the range of approved uses of OTC. The data suggest that the best treatment concentration of OTC for TD was $40 \mathrm{mg}$ OTC $\mathrm{kg}^{-1} \mathrm{crab}$ weight, which is lower than the concentrations approved for the treatment of salmonids. The mean survival rate at this concentration was $80 \%$ in the crab treatment experiments, although survival decreased with time. A significant decrease on the third day was found in Group 8 (Fig. 3), possibly resulting from the concentration of OTC being toxic to the crab. After several days the survival rate stabilized. Group 7 had the highest survival rate $(80 \%)$ in the treatment tests. Crabs were found to die in the positive control group 10 to $12 \mathrm{~d}$ after inoculation with spiroplasma in the absence of treatment with OTC. Approximately $65 \%$ of crabs died during these $3 \mathrm{~d}$, which is consistent with infection by spiroplasma (Wang et al. 2002). In general, crabs with TD had a high mortality rate (30 to $90 \%$ ), but the highest survival rate in the treatment experiments was $80 \%$. From this we conclude that OTC is a potent treatment for TD in farmed crabs.

The acute toxicity experiments determined that the 24 and $48 \mathrm{~h} \mathrm{LD}_{50}$ of OTC to the crabs were 366 and $340 \mathrm{mg}$ OTC $\mathrm{kg}^{-1}$ crab weight, respectively, and that the safe concentration was $82.5 \mathrm{mg}$ OTC $\mathrm{kg}^{-1}$ crab weight. The optimum concentration of OTC in the treatment of TD was $40 \mathrm{mg} \mathrm{kg}^{-1}$, which indicates that OTC can safely be applied for the treatment of this disease.

OTC is less expensive than deltamethrin, potassium permanganate, cupric sulfate pentahydrate, bromochlorodimethylhydantoin or calcium oxide and is effective at inhibiting spiroplasma. We suggest OTC for the treatment of TD to reduce the pathogenic risk to crabs, to increase the profits from crab farming and to raise farmers' enthusiasm. Other research has recently reported the presence of spiroplasma agents in marine shrimp (Nunan et al. 2004, 2005), suggesting that this pathogen has become a new and important agent in commercial aquaculture. The present study provides some valuable information on the prevention and treatment of spiroplasma diseases in these economically important crustaceans. However, further investigations, such as the pharmacokinetics and bioavailability of OTC in the crab, still need to be carried out.

Acknowledgements. This work was supported by grants from the National Natural Sciences Foundation of China (NSFC No. 30771649), the Research Program of Jiangsu Province of China (No. BE2007343) and the Natural Science Foundation of the Jiangsu Higher Education Institutions of China (No. 07KJD240105).

\section{LITERATURE CITED}

Anderson D, Jeney G (1992) Immunostimulants added to inject Aeromonas salmonicida bacterin enhance the defence mechanisms and protection in rainbow trout (Oncorhynchus mykiss). Vet Immunol Immunopathol 34:379-389

Bastian FO, Dash S, Garry RF (2004) Linking chronic wasting disease to scrapie by comparison of Spiroplasma mirum ribosomal DNA sequences. Exp Mol Pathol 77:49-56

Bjorklund H, Bylund G (1991) Comparative pharmacokinetics 
and bioavailability of oxolinic acid and oxytetracycline in rainbow trout (Oncorhynchus mykiss). Xenobiotica 21: 1511-1520

Bruun M, Schmidt A, Madsen L, Dalsgaard I (2000) Antimicrobial resistance patterns in Danish isolates of Flavobacterium psychrophilum. Aquaculture 187:201-212

Chen H, Xue R, Gong C (1999) Electron microscopic observation of spherical viruses in Eriocheir sinensis. J Fish Sci China 6:114-115

Chen MF, Apperson JA, Marty GD, Cheng YW (2006) Copper sulfate treatment decreases hatchery mortality of larval white seabass Atractoscion nobilis. Aquaculture 254: 102-114

Chopra I (1985) Mode of action of the tetracyclines and the nature of bacterial resistance to them. In: Boothe J, Hlavka $\mathrm{J}$ (eds) The tetracyclines (handbook of experimental pharmacology), Vol 78. Springer-Verlag, Berlin, p 317-392

Christensen NM, Axelsen KB, Nicolaisen M, Schulz A (2005) Phytoplasmas and their interactions with hosts. Trends Plant Sci 10:526-535

Clark T (1982) Spiroplasmas: diversity of arthropod reservoirs and host-parasite relationships. Science 217:57-59

> Corliss J, Lightner D, Eldin ZZ (1977) Some effects of oral doses of oxytetracycline on growth, survival and disease in Penaeus aztecus. Aquaculture 11:355-362

Dalsgaard I, Madsen L (2000) Bacterial pathogens in rainbow trout, Oncorhynchus mykiss (Walbaum), reared at Danish freshwater farms. J Fish Dis 23:199-209

> Delepee R, Pouliquen H (2003) Ion-paired solid phase extraction as a sample preparation strategy for the-high-performance liquid chromatographic determination of oxytetracycline in the bryophyte Fontinalis antipyretica. Anal Chim Acta 475:117-123

Delepee R, Pouliquen H, Le Bris H (2004) Bryophyte Fontinalis antipyretica Hedw. bioaccumulates oxytetracycline, flumequine and oxolinic acid in the freshwater environment. Sci Total Environ 322:243-253

Ding ZF, Bi KR, Wu T, Gu W, Wang W, Chen JX (2007) A simple PCR method for the detection of pathogenic spiroplasmas in crustaceans and environmental samples. Aquaculture 265:49-54

Hackett K, Ginsberg A, Rottem S, Henegar R, Whitcomb R (1987) A defined medium for a fastidious spiroplasma. Science 237:525-527

He J, He L, Zeng L (1999) A primary study on the tremor disease agent. Freshw Fisheries 29:10-11

Huang QY (2000) The actual studies on tremor disease of Chinese mitten crab. Sci Fish Farm 10:13-14

Levy SB (1984) Resistance to tetracyclines. In: Bryan L (ed) Antimicrobial drug resistance. Academic Press, New York, p 191-240

Lu H (1999a) Apicornavirus disease and histopathology of Eriocheir sinensis. J Fisheries China 23:61-68

Lu H, Jin LH, Fan LP (1999b) Isolation and identification of the bacterial pathogens in Eriocheir sinensis. Fish Sci 23:381-386

Lunden T, Lilius EM, Bylund G (2002) Respiratory burst activity of rainbow trout (Oncorhynchus mykiss) phagocytes is modulated by antimicrobial drugs. Aquaculture 207: 203-212

McCoy WF, Wireman JW (1989) Efficacy of bromochlorodimethylhydantoin against Legionella pneumophila in industrial cooling water. J Ind Microbiol Biotechnol 4:403-408

Miranda CD, Zemelman R (2002) Bacterial resistance to oxytetracycline in Chilean salmon farming. Aquaculture 212:31-47
Moulder RW, Frenchank FE, Chang CJ (2002) Simplified media for spiroplasmas associated with tabanid flies. Can J Microbiol 48:1-6

Nunan LM, Pantoja CR, Salazar M, Aranguren F, Lightner DV (2004) Characterization and molecular methods for detection of a novel spiroplasma pathogenic to Penaeus vannamei. Dis Aquat Org 62:255-264

Nunan LM, Lightner DV, Oduori MA, Gasparich GE (2005) Spiroplasma penaei sp nov., associated with mortalities in Penaeus vannamei, Pacific white shrimp. Int J Syst Evol Microbiol 55:2317-2322

Pan L (1998) Pathogeny and histopathological study on pectoral limb shiver disease in farmed Eriocheir sinensis. Fish Sci Technol Info 6:33-37

Reed LA, Siewicki TC, Shah JC (2004) Pharmacokinetics of oxytetracycline in the white shrimp, Litopenaeus setiferus. Aquaculture 232:11-28

Regassa LB, Gasparich GE (2006) Spiroplasmas: evolutionary relationships and biodiversity. Front Biosci 11:2983-3002

> Rigos G, Alexis M, Andriopoulou A, Nengas I (2002) Pharmacokinetics and tissue distribution of oxytetracycline in sea bass, Dicentrarchus labrax, at two water temperatures. Aquaculture 210:59-67

Rigos G, Nengas I, Tyrpenou AE, Alexis M, Troisi GA (2003) Pharmacokinetics and bioavailability of oxytetracycline in gilthead sea bream (Sparus aurata) after a single dose. Aquaculture 221:75-83

Saglio P, Hospital ML, Lafliche D, Dupont G, Bore JM, Tully JG, Freundt EA (1973) Spiroplasma citri gen. and sp. n.: a mycoplasma-like organism associated with 'stubborn' disease of citrus. Intl J Syst Biol 23:191-204

- Sanmartín Durán ML, Caamaño-García F, Fernández Casal J, Leiroa J, Ubeira FM (1989) Anthelminthic activity of praziquantel, niclosamide, netobimin and mebendazole against Bothriocephalus scorpii naturally infecting turbot (Scophthalmus maximus). Aquaculture 76:199-201

Shen J, Yin W, Qian D (2000) Studies on the pathogens of bacterial diseases of Eriocheir sinensis. J Fish Sci China 7: 89-92

Singhal RN, Jeet S, Davies RW (1986) Chemotherapy of six ectoparasitic diseases of cultured fish. Aquaculture 54: $165-171$

Sun X, Guo A, Lu C (2000) The artificial infection and recurrence of tremble disease of Chinese mitten handed crabs. J Nanjing Agricultural Univ 23:74-76

Takahashi Y, Itami T, Nakagawa A, Nishimura $H$, Abe T (1985) Therapeutic effects of oxytetracycline trial tablets against vibriosis in cultured kuruma prawns Penaeus japonicus BATE. Bull Jpn Soc Sci Fish 51:1639-1643

Tully JG, Whitcomb RF, Clark HF, Williamson DL (1977) Pathogenic mycoplasmas: cultivation and vertebrate pathogenicity of a new spiroplasma. Science 195:892-894

Ueno R, Kinoshita A, Wakabayashi J (2004) Comparative pharmacokinetics of oxytetracycline in eel and its fate in a closed aquatic environment. Aquaculture 235:53-63

USFDA (1996) Oxytetracyline. In: Code of Federal Regulations. US Government Printing Office, Washington, DC, p 443-446

> Wang W, Gu ZF (2002) Rickettsia-like organism associated with tremor disease and mortality of the Chinese mitten crab Eriocheir sinensis. Dis Aquat Org 48:149-153

Wang W, Zhu NN, Gu ZF, Du K, Xu ZK (2002) Study on the transmission of tremor disease (TD) in the Chinese mitten crab, Eriocheir sinensis (Crustacea: Decapoda). J Invertebr Pathol 81:202-204

Wang J, Zhu Q, Zhou G (2003a) Studies on Richettsia-like organisms infecting Eriocheir sinensis. Chin J Appl Envi- 
ron Biol 9:273-278

Wang W, Rong LW, Gu W, Du KH, Chen JX (2003b) Study on experimental infections of Spiroplasma from the Chinese mitten crab in crayfish, mice and embryonated chickens. Res Microbiol 154:677-680

Wang W, Wen BH, Gasparich GE, Zhu NN, Rong LW, Chen JX, Xu ZK (2004a) A spiroplasma associated with tremor disease in the Chinese mitten crab (Eriocheir sinensis). Microbiology 150:3035-3040

Wang W, Chen JX, Du KH, Xu ZK (2004b) Morphology of spiroplasmas in the Chinese mitten crab Eriocheir sinensis associated with tremor disease. Res Microbiol 155: 630-635

Wei ZN (1999) An investigation on the epidemiology of tremor disease of the Chinese mitten crab, Eriocheir sinensis. Freshw Fish 7:16-17

Whitcomb RF (1983) Culture media for spiroplasmas In: Tully JG, Whitcomb RF (eds) Methods in mycoplasmology. Academic Press, New York, p 147-158

WHO (World Health Organization) (1984) Molluscicide screening and evaluation. Bull WHO 33:567-581

Williams RR, Lightner DV (1988) Regulatory status of thera-

Editorial responsibility: Sven Klimpel,

Düsseldorf, Germany peutants for penaeid shrimp culture in the United States. J World Aquacult Soc 19:188-196

Williamson DL, Sakaguchi B, Hackett KJ, Whitcomb RF and others (1999) Spiroplasma poulsonii sp. nov., a new species associated with male-lethality in Drosophila willistoni, a neotropical species of fruitfly. Int J Syst Bacteriol 49:611-618

$\mathrm{Xu} \mathrm{HS}, \mathrm{Xu} \mathrm{BJ}$ (2002) Isolation and Identification of the bacterial pathogens in Eriocheir sinensis. Chin J Vet Sci 22: 137-139

Yang X, Cai W (1998) Primary survey on the epidemic of shiver disease of Chinese mitten-handed crab. Technol Info Aquacult 25:278-279

Yuan X (2005) China national fishery statistic and analysis in 2004. Fish Wealth Guide 13:13-16

Zar JH (1999) Biostatistical analysis. Prentice Hall, Upper Saddle River, NJ

Zhang F, Wang J, Zhu Q (2002) Electron microscopy of pathologen of appendage shaking disease of Eriocheir sinensis. J Dalian Fisheries Univ 17:336-340

Zhou H, Yang W (2000) A review of study on pectoral limb shiver disease in Chinese mitten crab. Fish Sci 19:28-29

Submitted: January 10, 2008; Accepted: February 17, 2009

Proofs received from author(s): April 18, 2009 